\title{
Research on the Countermeasures of Development of Ice and Snow Tourism in Changchun
}

\author{
Mingju Liu \\ Yatai School of Business Administration \\ Jilin University of Finance and Economics \\ Changchun, China 130117
}

\author{
Liguang Zhao \\ School of Taxation \\ Jilin University of Finance and Economics \\ Changchun, China 130117
}

\author{
Dandan Zhang \\ Yatai School of Business Administration \\ Jilin University of Finance and Economics \\ Changchun, China 130117
}

\begin{abstract}
Jilin Province is the main base of ice and snow tourism and Changchun City as the capital city of Jilin Province, is the economic, political, cultural and transportation center of Jilin Province. Changchun has a unique geographical location and climatic conditions as well as rich cultural deposits, with the advantages of winter tourism. But under the condition of fierce market competition, the humanistic tourism resources including architecture, transportation, and local specialties also need urgent integration and development. The development of ice and snow tourism in Changchun City also faces opportunities and challenges. Based on the analysis of the current situation of ice and snow tourism in Changchun City, this paper points out the existing problems of ice and snow tourism, and then puts forward the solving strategies.
\end{abstract}

Keywords-Changchun; ice and snow tourism; development countermeasure

\section{INTRODUCTION}

Changchun successfully held the ice and snow tourism festival in 2008. Since the first snow and ice tourism festival in 1998, Changchun Ice and Snow Tourism Festival has gone through 11 years. Over the past 11 years, Changchun Ice and Snow Festival have exerted a great impact at home and abroad. Making full use of ice and snow tourism resources plays an extremely important role in developing and expanding tourism industry in Changchun, promoting foreign exchange and economic and trade cooperation, creating a harmonious social atmosphere and accelerating the revitalization of old industrial base in Changchun. Ice and snow tourism as one of the most popular tourism projects in northern China not only promotes the physical and mental health of citizens and improve the living quality, but also enhance the regional economic development.

Fund Project: National Natural Science Foundation of China (Project No.: 41401146); Science and Technology Development Project of Jilin Province (201502040NY). Project of Education Department in Jilin (JJKH20170140SK)

\section{AN OVERVIEW OF ICE AND SNOW TOURISM}

\section{A. The Concept of Ice and Snow Tourism}

At present, the common definitions of snow and ice tourism at home and abroad are as follows: Du Qingzhen thinks that "ice and snow tourism is the Mountain vacation tourist product integrating participation, fun and irritation based on the winter snow resources"; Zhang Decheng points out that "ice and snow tourism is the wild activity that returns to nature, challenges ourselves, build our body, provides entertainment, and enhance knowledge and cultivate the temperament"; Li Yi holds that "ice and snow tourism is the high-level consumer activity that can meet people's material and spiritual needs through experience icing and snow culture in the form of snow sports, which belongs to the category of ecotourism and forest tourism."

It can be seen that scholars have recognized the snow tourism has the common character of sport tourism in the studies. Therefore, we can define snow and ice tourism as the tour activity that takes snow and ice sports as the objective of main activity content. Snow tourism refers to a comprehensive tourism activity that people do in the snow and ice environment, which is a way of leisure by experiencing ice and snow culture in a short period. It mainly includes snow and ice fitness and appreciation, appreciation of ice and snow arts, ice and snow culture entertainment, and snow and ice folk activities.

\section{B. The Characteristics of Ice and Snow Tourism}

1) Regionalism: As the formation and existence of ice and snow resources is affected and restricted by the geographical environment, ice and snow tourism resources are mainly distributed in the poles of the Earth and mid and high latitudes, with a clear regionalism. It is the regionalism of ice and snow resources that makes it a resource with geographical advantage. In China, the snow and ice resources are mainly distributed in the northeast, north and 
northwest regions. Especially in the northeast region where the snow and ice resources is very widely distributed, ice and snow tourism has not been developed, which creates a very good resource conditions.

2) Participation nature: Ice and snow tourism has strong participation, which is determined by its own origin and the travel needs of tourists. The utilization and exploitation of ice and snow resources is originated in the daily activities of ancient people. On the other hand, people expect to be able to participate in the snow and ice activities together in the cold winter, so just observing the static snow and ice landscape is not enough.

3) Fitness nature: Skiing is an important part of ice and snow tourism. Participating in skiing activities can not only exercise one's body and improve health, but also adjust the pressure brought about by the work, helping people get rid of insipid work to relax and improve physical health.

4) Experience nature: When winter comes, the northern tourists can enjoy the scenery of a thousand leagues of whirling snow, indulge in the white snow to experience the true essence of ice and snow tourism and ski in the snowy forest with passion to enjoy the pleasure of freedom; they can ride a snow motorcycle at high speed on the endless snow surface; mount on the horses to gallop in the vast grasslands and feel the joy of lives of herdsmen; sit on the dog sledge to run on the surface of the ice and snow to feel another different fresh pleasure.

5) Dependence nature: The development of ice and snow tourism has a strong dependence on resources which must possess cold weather conditions and suitable terrain conditions, because although some countries are located in the cold temperate and mid temperate zone, they cannot establish a ski resort for lack of suitable slope.

6) High consumption: As the snow and ice tourism has a high re-visit rate, guests participating in skiing have to pay high cost for the equipment, coupled with the high cost of catering and accommodation in holiday travel. Therefore, ice and snow tourism has high tourism consumption.

\section{The CURRENT SituATION AND AdVANTAGES OF ICE AND SNOW TOURISM IN CHANGCHUN}

\section{A. The Current Situation of Ice and Snow Tourism in Jilin Province}

Changchun is rich in snow and ice resources with unique charm, which makes winter tourism an important feature and outstanding highlights of tourism in Changchun with the help of external factor "Vasa International Ski Festival". Changchun as an outstanding ice and snow tourism city in China, gives full play to the important destination and distribution center of ice and snow tourism in northern China, actively integrates the advantages of resources, introduces internationally renowned brands and promotes the development of industrial innovation. At present, Changchun Ice and Snow Tourism Festival in China and Jingyuetan Vasa International Ski Festival has developed into a largescale tourism festivals with wide range of participation, international popularity, and love of masses, which sets a good example in China.

With the continuous development of ice and snow tourism resources, the development and utilization of ice and snow tourism products in Changchun are gradually enriched. There are not only the natural ice and snow landscape such as rime and skating rink, but also artificial snow and ice landscape like snow sculpture and ski resort. Ice and snow sports include skating, snowmobile, and dog sledge and so on. Currently, the scenic areas themed on snow and ice tourism products in Changchun in winter are mainly Jingyuetan Vasa Ski Resort and snow sculpture garden. Lianhuashan Ski Resort adds the ice and snow entertainment facilities as well as supporting projects of skiing suitable for the masses based on the original ski facilities, making it gradually develop to the comprehensive ski resort. In recent years, New Miao Shan Township ski resort and Xinli Lake ski resort are the tourist bases taking skiing as the main project. Skiing as one of the main types of ice and snow tourism has a strong relevance and great growth.

At present, the consumers of skiing tourism in Jilin Province are mostly tourists of the province, and among them students and staffs of administrative institutions occupy the vast majority, composing the most stable source of tourists of the ski tourism in Jilin Province. Snow and ice tourism has a great relevance. The current snow and ice tourism industry in Changchun City can only be said to take shape, with a series of supporting industrial facilities yet to be established and the new planning that guides the snow and ice tourism industry is still in the drafting stage. For example, the industrial chain of clothing and machinery related to snow and ice tourism activities has not yet been fully built. It can be seen that snow and ice industry chain in Changchun City is still to be perfect, and snow and ice tourism can't drive the entire tourism industry.

\section{B. The Advantages of Ice and Snow Tourism in Changchun}

1) Geographical advantage: Ice and snow tourism is tourism products with the most distinctive characteristics of the North. It integrates sightseeing, fitness, and entertainment, which is popular with tourists. Northeast region has cold winter and heavy snowfall due to the high latitudes, so the unique weather conditions make the Northeast become the region with most abundant ice and snow tourism resources, especially Heilongjiang and Jilin provinces. Located in the transitional zone of northeast mountain and Songnen Plain, Changchun has mountains, hills, plains and tableland. Terrain with different slopes and the cold climate provides very favorable conditions for the implementation of ice and snow tourism. From the perspective of integration of ice and snow tourism resources and creation of fine lines, it has the advantages of excellent geographical location and tourism distribution center. Changchun exactly seizes its regional advantages to highlight its characteristics. The reputation and unique geographical location, climatic conditions, abundant natural resources and historical legacy of civilization bring the 
opportunity to development of winter tourism resources in Changchun.

2) Advantages of climatic conditions: Changchun accumulates snow for nearly half a year, with the average thickness of snow of $20 \mathrm{~cm}$, so it has the best weather conditions to develope ice and snow tourism, snow and ice sports in China. The unique natural condition is also very rare in China. The soft, white, elastic snow that is suitable for skiing and sculpture is the best outdoor environment for the development of skiing and snow sculpture art in China. Long winter, long snowfall period, large snowfall, pure snow quality, and the environment that is suitable for snow sculpture, skating, and skiing are the industry advantages of development of ice and snow tourism.

3) Traffic conditions: Changchun as the capital of Jilin province is the political, economic, transportation, cultural center of Jilin. Jilin Province is constructing the air traffic structure of "one main and four auxiliary". The so-called "one main and four auxiliary" refers to Changchun Longjia International Airport as the main airport, Jilin, Yanji, White Mountain Airport under construction and the airport in the Northwest region under observation as the sub-line airport. Changchun Longjia Airport has opened domestic flights to Jinan, Shenzhen, Shanghai, and Beijing and so on, and the international flights to Russia, South Korea, and Japan. Railway in Changchun can directly reach Harbin, Shenyang, Dalian, Beijing, Tianjin, Jinan, Shanghai and other major cities nationwide.

4) The brand awareness created by well-known sports events: Changchun is rich in ice and snow tourism resources, which can be both watched and played; tourists can enjoy ice lantern, ice sculpture, and skate and ski. Jilin City is one of earliest cities that carry out ice and snow tourism activities in Jilin Province. The Songhua River flows from the southwest to the southwest, forms "Pipa Bay" in urban area and then flows towards the northwest. The river still does not frozen in the temperature of thirty centigrade below zero, with the pines and willows on both sides of shores hanging snow, which forms one of the four wonders of China - Jilin rime. However, compared with Jilin City, ice and snow tourism resources of capital Changchun is known better for the rich cultural atmosphere. Changchun Jingyuetan Vasa Ski Festival has become a well-known brand of ice and snow tourism festivals in China. Changchun won the right to host Asian Winter Games in 2007, which is another victory of Chinese sports following Beijing obtaining the right to host 2008 Olympic Games. The facts fully shows that the future of snow and ice sports and tourism in Changchun is promising and in the ascendant.

\section{ANALYSIS OF THE SNOW AND ICE TOURISM IN CHANGCHUN}

\section{A. Insufficient Promotion of Ice and Snow Tourism and Low Popularity}

Although the snow and ice tourism in Jilin Province has a certain reputation at home and abroad, the market has not been fully developed. The government lacks the overall strategic awareness of shaping the ice and snow tourism brand of Jilin, has not established the overall image of snow and ice tourism of Jilin Province, and the existing resources also hasn't been fully exploited and utilized, so snow and ice tourism project appears monotonous. The investment in manpower and financial resources and publicity efforts is not enough. Although the natural environment in Changchun City is better than Harbin, the popularity of ice and snow tourism is significantly lower than Harbin. There is no projects like ice lantern and ice sculpture in Harbin that is familiar to visitors at home and abroad. In addition to Jingyuetan Ski Resort and Lianhua Hill Ski Resort that have a certain scale and popularity, other ski resorts in Changchun are less famous. People of the province know well that compared with the ski and snow festival in Heilongjiang, their popularity is much less. It is known that this year investment in construction of Jingyuetan ice and snow products will increase, with the snow and ice products covering an area of 100,000 square kilometers, and snow production is expected to reach 500,000 cubic meters, which is twice as much as that of last year. The Jingyue snow world covers an area of 8 million square meters, with 400,000 cubic meters of snow. Product system of four regions are planned and designed in Jingyuetan scenic area, which are respectively the viewing area of snow sculpture art, Vasa cultural exhibition area, and snow sports area. Based on the continuation of the previous European style experience, Chinese elements and visitor's interaction are added to enrich product content, striving to build the fairy tale world in winter for visitors to feel different winter. However, such large-scale construction is not poorer than the building of Harbin Ice-Snow World but it is not as popular as Harbin Ice-Snow World with tourists. Except some skating rinks like Changchun Wuhuan Gymnasium that is developed relatively perfect, other skating rinks are poorly developed.

\section{B. The Lack of Overall Planning and Supporting Facilities}

In recent years, with the development of ice and snow tourism, everywhere has built a variety of snow and ice recreation facilities, but they generally lack unified requirements and planning and most of them are repeated construction with a low level and low standard, leading to the scene of where there is mountain, there is ski resort. The quality of most employees is not high since many of them are the residents from the neighborhood and relatives of the staffs in scenic area. They do not master professional tourism knowledge, so the quality of service and work cannot meet the needs of more and more tourists, thus affecting the sustainable development snow and ice tourism in Changchun. Ice and snow tourism industry not only includes skating and skiing, transportation, accommodation, catering, shopping 
souvenirs, business and cultural activities, but the Internet, medical treatment and security, etc., should also be matched.

\section{The Lack of a Unified Scientific Management}

In recent years, ice and snow tourism has been listed in the industries that need key support and development in Jilin Province. Changchun City as a key developing city, has introduced the relevant policies and regulations, with very fast pace of development. But ice and snow tourism still lacks the overall planning from the aspects of development, construction and management, especially the disorderly development and establishing ski rink without permission. And the relevant necessary facilities and equipment cannot keep up, and professionals are insufficient, coupled with the manager's business awareness, legal concepts and guiding ideology still have some bias, leading them exclude each other and work in their own way, just for their own personal economic interests, which shows a chaotic state, damaging the overall image of snow and ice tourism in Changchun.

\section{Integration of Ice and Snow Tourism and Culture is Poor}

In contrast to the continuous improvement of the ice and snow tourism project infrastructure, the Ice and Snow Tourism Project in Changchun still lacks its own cultural personality. Most of the projects are dominated by foreign culture and traditional culture while lack subjective culture with distinctive characteristics. For example, the integration of ice and snow tourism and regional cultural characteristics in Changchun is not enough. Changchun is the home of the Museum of the Imperial Palace of the Manchu State at the end of Qing Dynasty, the living place of the last Emperor Pu Yi's as well as the birthplace of the shaman culture, so how to combine the culture of the Manchukuo period with the ice and snow tourism culture and combine shaman culture with ice and snow tourism to improve the acknowledge of people around the country and the world towards snow and ice tourism in Changchun, and how to highlight the innovation and cultural property of construction of snow and ice tourism project is the crucial problems that need to solve currently.

\section{ANALYSIS OF COUNTERMEASURE ON THE SNOW AND ICE TOURISM IN CHANGCHUN}

\section{A. Strengthen Promotion, Build Brand, and Improve Popularity}

We should strengthen the promotion work. The natural conditions and hardware measures of snow and ice tourism in Changchun are not worse than Harbin, but the number of tourists and income in winter is far less than Harbin, which is mainly due to poor promotion and the lack of brand-name products, resulting in lower popularity among domestic and foreign tourists.

Changchun holds a number of snow and ice festival activities every year, such as Changchun Ice and Snow Tourism Festival and Jingyuetan Vasa Ski Festival and Changbai Mountain International Ice and Snow Culture and Tourism Festival in China that are well-known large-scale ice and snow activities. These are opportunities to publicize ice and snow tourism in Changchun in order to establish the image of Changchun City as the ice and snow tourist destination in China and enhance the status of snow and ice tourism in Changchun in the whole snow and ice tourism industry. We can also use the effect of famous human and natural resources in the province such as one of the four major landscape in China — "Jilin Rime" and Changbai Mountain to promote and develop a fine tourism hotline in Changchun with unique charm and create distinctive snow and ice tourism brand in Changchun City. We need to meet the needs of ice and snow tourists of different levels and different types. And we should also vigorously develop domestic and foreign markets, cultivate the sense of participation of young people, build a multi-level market structure, and establish "Changchun tourism website" with a variety of languages to promote featured products. Moreover, we can use celebrity effects and modern information technology like Internet technology, timely and widely publicize ice and snow tourism industry in Changchun, make ice and snow tourism market in Jilin Province bigger and stronger, enhance the attractiveness and actually transform advantages of resources into industrial advantages to promote the construction of relevant ice industry chain and push the snow and ice tourism in Changchun to China and the world.

\section{B. Strengthen the Construction of Relevant Supporting Facilities}

The snow and ice tourism projects that can satisfy the tourists need the continuous improvement and construction of the supporting industries including catering, accommodation, traveling and shopping and so on in addition to complete infrastructure of the project itself. First of all, we can bring the service system of the major business circles in Changchun into the service system of ice and snow tourism industry to operate concretely, appropriately extend the opening hours of shops in winter or introduce some ice and snow tourism projects to the bustling business district, in order to attract more tourists. Second, we need to further improve the ice and snow tourism facilities, including the rational allocation of rescue facilities and staff, fight for the normal operation of rescue facilities, smooth communication, and smooth rescue channels.

\section{Improve the Management Level and Strengthen the Training of Ice and Snow Project Professionals}

With the snow and ice tourism getting more and more popular and continuous normalization of relevant industries, we not only need to improve the hardware conditions of the relevant facilities, but also should further enhance the software management of ice and snow tourism employees. At present, professionals related to the ice and snow tourism are very scarce, which seriously restricts the further development of the industry, so we must firstly improve the level of economic management, strengthen service awareness, and improve the comprehensive service level. We should also continue to introduce high-level economic management personnel, and make full use of the advantageous resources of university education. We will 
strengthen the training of relevant staff, take the high-level ice and snow tourism at home and abroad as the standard to learn its advanced experience and provide professionals for ice and snow tourism market in Changchun to ensure the scientization and professionalization of ice and snow tourism market. Thus we can improve the quality of service to achieve sustainable development of the industry. Warm and thoughtful service and elegant environment will attract the travel enthusiasts to visit, drive consumption, and promote the development of local economy.

\section{Combine with the Culture within the Changchun Area to Form Unique Snow and Ice Tourism Brand}

The rapid development of ice and snow tourism industry has brought ice and snow tourism into the brand era, so how to build valuable brand is the key to the rapid development of snow and ice tourism industry in Changchun City. If we want to have a place in the current increasingly competitive ice and snow tourism industry, we must have our own characteristics. We should combine the cultural characteristics with the ice and snow tourism, carry out large-scale operation and scientific management, and scientifically position our own brands to improve competitiveness by combining with our own advantages. In regard to the development of ice and snow tourism project Changchun, we should combine with the advantageous resources of Changchun, emphasize the integration of snow and culture, sports and art, and create the ice and snow tourism projects with distinctive characteristics and rich content in the aspects of ice and snow sightseeing and leisure, ice and snow events, combination of snow festival and folklore.

\section{E. Government Should Strengthen the Scientific Planning and Management of Snow and Ice Sports Tourism}

Strictly speaking, ice and snow tourism industry is an industrial chain, which is a huge economic complex system taking snow and ice tourism resources as the main body and related industries as auxiliary. In order to make it an organic whole to create the greatest benefits, the functional departments of government play indispensable important role and the relevant supportive policy is also particularly important, which highlights the importance of macroeconomic regulation and control. The development of ice and snow tourism must be led by government to scientifically plan, develop and construct ice and snow tourism industry. Thus we can prevent the waste and damage of resources brought by repeated construction. Government can provide support in policy and finance, actively encourage social investment, introduce the investment of enterprises and foreign capital to develop ice and snow tourism market through multi-channel financing, increase investment in ice and snow tourism, and carry out macrocontrol in related facilities, and gradually adjust and improve the industrial structure to achieve large scale and conglomeration, which is conducive to the formation of ice and snow tourism industry system, comprehensively enhancing the competitiveness of snow and ice tourism in Changchun and achieving sustainable development of snow and ice tourism in Changchun. At the same time, tourism enterprises should work closely with the relevant departments, actively absorb foreign advanced management experience, and make feasible development planning aiming at the needs of tourists towards the ice and snow tourism to promote the improvement and development of enterprises.

\section{CONCLUSION}

With the development of market economy, people's living quality gradually increases, making more and more people participate in traveling outside. Accompanied by the flourish and standardization of tourism industry, tourists are transforming from simple sightseeing tour to various special tourism. Changchun of Jilin Province is located in the middle of northeast China, the "platinum belt" rich in snow and natural resources, so it has unique geographical location and advantageous climatic conditions, which make ice and snow tourism developed rapidly. Snow and ice fitness and enjoyment, ice and snow art appreciation, ice and snow culture entertainment, and snow and ice folk activities are all belong to snow tourism that as a new fashion of tourism products, integrates sightseeing, vacation, shopping, business and sports, entertainment and leisure into one, with high irritation and challenge. Ice and snow tourism of Changchun City will face greater opportunities and challenges.

\section{REFERENCES}

[1] Zhang Na. Study on Economic Effect and Regulation of ice and snow tourism in Northeast China. Northeast Normal University, 2012.

[2] Wang Jing. Reconstructing the New Advantages of Ice and Snow Tourism Development in Heilongjiang Province. China winter sports, 2012 (9).

[3] Liu Mingju, Yuan Fang. Reflecations on the Study of Tourism Resources Taxation and Economy, 2016 (1)

[4] Bai Xue. Innovative Development of Ice and Snow Tourism Industry in Jilin Province from the Perspective of Cultural Industry China winter sports, 2016 (5)

[5] Shao Shuai. SWOT Analysis of Development of Ice and Snow Tourism in Jilin Province. Tourism Overview, 2016 (1).

[6] Zhao Li. Cultivate "ice and snow tourism" cultivated into a famous international tourism brand. China tourism news, 2016 (12). 